\section{DESCRIÇĀO DE UM NOVO FOCO ENDÊMICO DE ESQUISTOSSOMOSE MANSÔNICA NO ESTADO DE SÃO PAULO, BRASIL}

\author{
Afonso Dinis Costa Passos * \\ José da Rocha Carvalheiro * \\ Uilho Antonio Gomes * \\ Edna Teruko Kimura ** \\ Gilson Freitas da Silva** \\ Helena Takako Sato ** \\ Heloisa Bettiol ** \\ Josefina Mercedes Conti Maimone ** \\ Joselita Aparecida Vilares** \\ Leda Uemura ** \\ Lélia Nogueira Rodrigues Alves *:* \\ Maria Deolinda Martins **
}

Passos, A. D. C. et al. Descrição de um novo foco endêmico de esquistossomose mansônica no Estado de Sáo Paulo, Brasil. Rev. Saúde públ., S. Paulo, 13: $341-7,1979$.

RESUMO: Foi descrito novo foco endêmico de esquistossomose mansônica situado na Cidade de Bebedouro, Estado de São Paulo, Brasil. Foram analisados 221 casos diagnosticados da doença segundo a idade, sexo e origem (autóctone ou não), bem como foram discutidos os fatores envolvidos no aparecimento do foco, alertando-se para a necessidade de medidas de controle.

Unitermos: Esquistossomose mansônica, S. Paulo, SP, Brasil.

\title{
INTRODUÇAO
}

Entre as chamadas endemias rurais, a esquistossomose mansônica vem dia a dia aumentando a sua importância em saúde pública em nosso meio. Muito embora o elevado número de parasitados existente no $P$ ais não traduza uma igual quantidade de formas graves da doença ${ }^{2}$, chama a atenção o caráter francamente expansivo da endemia ao longo do território nacional 1.3 .5 .
Os movimentos migratórios constantes, motivados pela busca de melhores condições de trabalho por parte de mão de obra não especializada, com a conseqüente localização de grandes contingentes populacionais na periferia das cidades, justifica o porquê da doença estar em franca disseminação e explica a transferência crescente da mesma do meio rural para o urbano $1,6, ?$.

* Do Departamento de Medicina Social da Faculdade de Medicina de Ribeirão Preto - USP - 14100 - Ribeirão Preto, SP - Brasil.

* Da Faculdade de Medicina de Ribeirão Preto - USP (Alunos - 5\% ano, 1979). 
PAssos, A. D. C. et al. Descrição de um novo foco endêmico de esquistossomose mansônica no Estado de São Paulo, Brasil. Rer. Saúde píbl., S. Paulo, 13:341-7, 1979.

A integração nas correntes migratórias de trabalhadores e seus familiares provenientes de areas de alta endemicidade e a presença de condiçōes ecológicas favoráveis para o desenvolvimento da doença nos locais onde esses migrantes se estabelecem, aliadas às precárias condiçōes de saneamento desses lockais e ao baixo nível sócio-econômico dos migrantes, têm sido os principais fatores responsáveis pelo aparecimento de focos da doença em áreas anteriormente indenes, fazendo prever o surgimento, a médio prazo, de novas regiōes endêmicas propagadoras da doença.

A 6" Kegião Administrativa do Estado de São Paulo, tendo por sede a cidade de Ribeirão Preto, compreende 80 municipios vizinhos e se caracteriza por intensa atividade agrícola, tendo atraido nos últimos anos um apreciável contingente de migrantes, em particular nordestinos.

Embora episódios de esquistossomose já tivessem sido relatados na região, anteriormente, foi em fevereiro de 1976 que se confirmou o aparecimento do primeiro caso autóctone, ocorrido na área urbana do municípin de Bebedouro 4. A bacia hidrográfica dessa cidade é composta por pequenos córregos, um dos quais é represado dentro do perimetro urbano, dando origem a um lago artificial utilizado pela população como àrea de lazer. Um levantamento iniciado em 1976 pela "Campanha de Combate à Esquistossomose" (CACESQ) e pelo Centro de saúde local evidenciou a presença de moluscos transmissores da esquistossomose (Biomphalaria tenagophila) nessas coleçöes de águas, bem como permitiu o diagnóstico de 221 casos da doença no periodo compreendida entre os meses de março de 1976 a fevereiro de 1979 , dos quais 176 foram considerados autóctones. $\mathrm{Na}$ presente publicação são analisadas algumas características epidemiológicas desse novo foco da doença, o que servirá como ponto de partida para a realização de um estudo mais abrangente sobre a endemia na 6" Região Adninistrativa do Estado de São Paulo

\section{MATERIAL E MÉTODOS}

Foram estudadas as fichas epidemiológicas dos 221 casos de esquistossomose mansônica diagnosticados durante o periodo de março de 1976 a fevereiro de 1979 , de onde se retiraram as seguintes informações: nome, sexo, idade, endereço, local de nascimento e procedência (autóctone ou não). Como todos esses dados haviam sido obtidos por pessoal não médıco (enfermeiras e visitadoras sanitárias), sentiu-se a necessidade de testar a informação referente à autoctoneidade dos casos. Mediante uma amostragem sistemática obteve-se um total de 39 casos que foram entrevistados pessoalmente por um médico epidemiologista e por estudantes do 5" ano da Faculdade de Medicina de Ribeirão Preto, visando medir a sensibilidade e especificidade da informação de ser ou não autóctone. Foram considerados como autóctones os individuos que apresentaram história pregressa de contacto com o lago e que preencheram a condição de terem sempre residido em Bebedouro ou de nunca terem habitado áreas reconhecidamente endêmicas de esquistossomose.

\section{RESULTADOS}

A Tabela 1 mostra o número de casos diagnosticados de acordo com o ano em que o diagnóstico foi realizado. Verifica-se que a grande maioria dos casos foi detectada durante o ano de 1976, caindo progressivamente nos anos seguintes.

A determinação da sensibilidade e especificidade da informação paramédica referente à origem dos casos (autóctones ou não) mostra valores de $97 \%$ e $100 \%$, respectivamente (Tabela 2).

A dıstribuição dos casos autóctones e alóctones segundo o sexo é mostrada na Tabela 3. Observa-se que os autoctones sáo quase 4 vezes mais freqüentes que os alóctones (176 e 45 respectivamente), e que o sexo masculino representa $93,2 \%$ do total de casos contra $6,8 \%$ do sexo femi- 
PASSOS, A. D. C. et al. Descrição de un novo foco endêmico de esquistossomose mansónica no Estado de São Paulo, Brasil. Rer, Saúde públ,, S. Paulo, 13:341-7, 1979.

nino. Entre os autóctones ocorre um predominio absoluto dos homens sobre as mulheres $(99,4 \%$ e $0,6 \%)$, elevando-se a participação feminina a $31,1 \%$ entre os alóctones $\left(\mathrm{x}^{2}=52,84 \mathrm{p}<0,01\right)$.

A Tabela 4 mostra a distribuição dos casos segundo a origem, sexo e idade. A maior concentração do total de parasitados ocorre na faixa etária de 15 a 19 anos $(37,1 \%)$, seguida de perto pelo grupo situado entre 10 e $14(36,2 \%)$. As demais faixas etárias contribuem com percentagens progressivamente menores à medida que se afastam das duas anteriores, para mais ou para menos. Entre os autóctones mascu-
T A B E L A 1

Número de casos de esquistossomose mansônica diagnosticados na cidade de Bebedouro, segundo 0 ano em que o diagnóstico foi realizado.

\begin{tabular}{ccc}
\hline & \multicolumn{2}{c}{ Total de casos } \\
\cline { 2 - 3 } Ano & No & 70 \\
\hline 1976 & 180 & 81,4 \\
1977 & 25 & 11,3 \\
1978 & 12 & 5,4 \\
$1979 *$ & 4 & 1,8 \\
\hline Total & 221 & 100,0 \\
\hline
\end{tabular}

* Atŕ $16 / 02 / 79$

T A B E L A 2

Determinaçăo da sensibilidade e especificidade da informaçăo médica referente autoctonejdade dos casos.

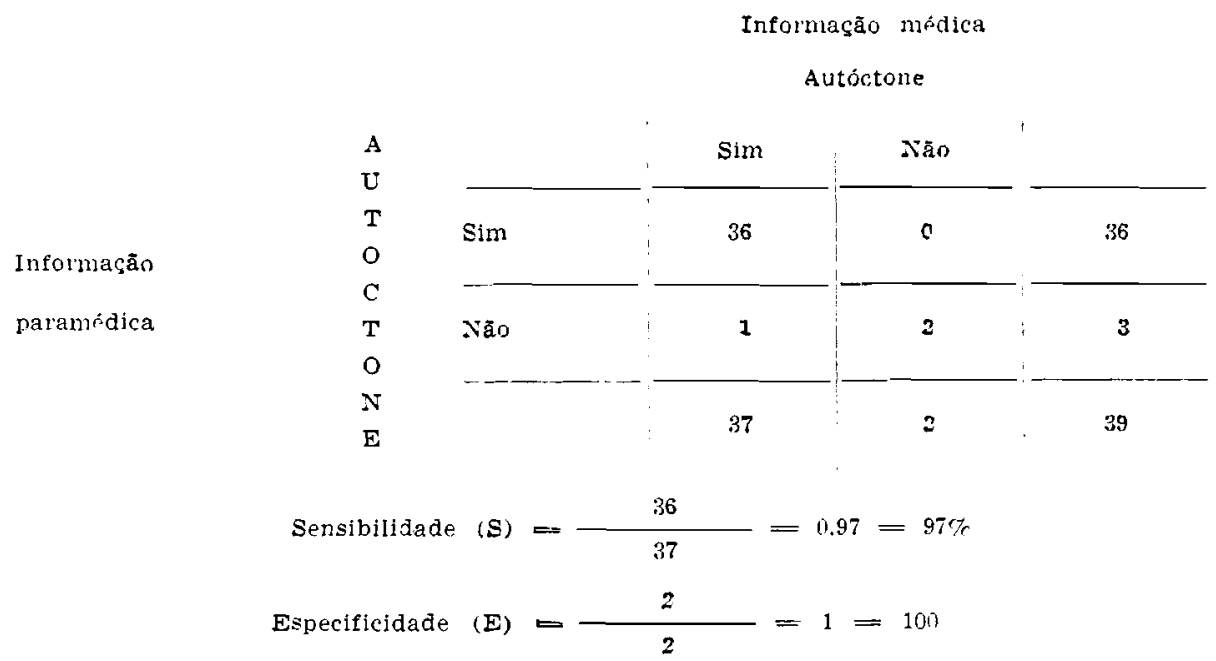

linos as idades mais comprometidas são as situadas entre 10 e 14 anos $(43,4 \%)$ e entre 15 e 19 anos $(39,4 \%)$. Seguem-se, pela ordem, os grupos de 20 a 24 anos $(8,0 \%), 25$ a $29(5,1 \%), 5$ a $9(2,3 \%)$ e 30 e mais $(1,7 \%)$, não ocorrendo nenhum caso entre 0 e 4 anos.
O único caso do sexo feminino está situado na faixa entre 15 e 19 anos.

Entre os alóctones do sexo masculino a maior concentração situa-se nas idades entre 15 e 19 anos $(29,0 \%)$, seguida pelos grupos de 25 a $29(19,4 \%), 20$ a 24 $(16,1 \%), 30$ e mais $(12,9 \%), 5$ a 9 e 10 
PASSOS, A. D. C. et al. Descrição de un novo foco endêmico de esquistossomose mansónica no Estado de São Paulo. Brasil. Rev. Saúde públ., S. Paulo. 13:341-7, 1979.

TABELA 3

Distribuição dos casos de esquistossomose mansônica segundo o sexo e a origem (autóctones alóctones), diagnosticados na cidade de Bebedouro nos anos de 1976 a $1979^{\circ}$.

\begin{tabular}{|c|c|c|c|c|c|c|}
\hline \multirow{2}{*}{ Sexo } & \multicolumn{2}{|c|}{ Autóctones } & \multicolumn{2}{|c|}{ Alóctones } & \multicolumn{2}{|c|}{ Totai } \\
\hline & $N^{\circ}$ & 76 & $N$ & $\%$ & $N^{\circ}$ & $\%$ \\
\hline Masculino & 175 & 99,4 & 31 & 68,9 & 206 & 93.2 \\
\hline Feminino & 1 & 0.6 & 14 & 31,1 & 15 & 6.8 \\
\hline Total & 176 & 100,0 & 45 & 100.0 & 221 & 100,0 \\
\hline
\end{tabular}

* Até $16 / 02 / 79$

$\mathrm{x}:=52.84 \mathrm{p}<0.01$

a $14(9,7 \%)$ e 0 a $4(3,2 \%)$. Dos 14 casos aloctones do sexo feminino $50 \%$ estão no grupo de 30 e mais anos, distribuindo-se os restantes irregularmente nas outras faixas etárias.

\section{DISCUSSÁO}

A cidade de Bebedouro tem recebido nos últimos anos um afluxo considerável de migrantes nordestinos, provenientes em especial de regiōes endêmicas de esquistossomose mansônica do Estado da Bahia. As condições de saneamento ambiental na periferia da cidade são deficientes, ocorrendo lançamento de esgotos diretamente no lago artificial e riachos próximos, os quais são procurados como opção de lazer pelas faixas da população de mais haixo nivel sócio-econômico.

Após a confirmação, em fevereiro de 1976. do primeiro caso autóctone da doença na cidade de Bebedouro, uma ampla busca de casos foi desencadeada pela "Campanha de Combate à Esquistossomose" (CACESQ). Lamentavelmente essa atividade cessou por completo a partir de 1977, o que serve, em parte, como explicação para a queda progressiva do número de casos diagnosticados a partir de então (Tabela 1).

Os resultados de $97 \%$ e $100 \%$ referentes respectivamente à sensibilidade e especifici- dade da informação relativa à autoctoneidade dos casos (Tabela 2), permite que tal informação seja aceita como fidedigna e possa ser generalizada.

O predominio absoluto do sexo masculino entre os casos autóctones (Tabela 3) pode ser explicado pela maior exposição ao risco, uma vez que são individuos desse sexo que com maior freqüência tem contacto com coleçōes de águas.

O alto percentual de participação feminina entre os alóctones $(31,1 \%)$ sugere a existencia de outros fatores de risco (profissionais, por exemplo) nas suas áreas de origem.

A maior concentração de casos autóctones no sexo masculino entre as idades de 10 a 19 anos (Tabela 4) também pode ser explicada pela maior exposição ao risco, em consequêencia de ser esse segmento da população o que mais assiduamente procura coleçōes de águas como opção de lazer.

Esses dados sugerem também que a transmissão da esquistossomose na área iniciou-se em época recente, pois do contrário as idades mais elevadas deveriam apresentar um numero de casos maior que os verificados, tal como ocorre entre os alóctones. Nesses, a participação fenıinina mais acentuada, em especial acima de 30 anos, reforça a idéia de envolvimento de 


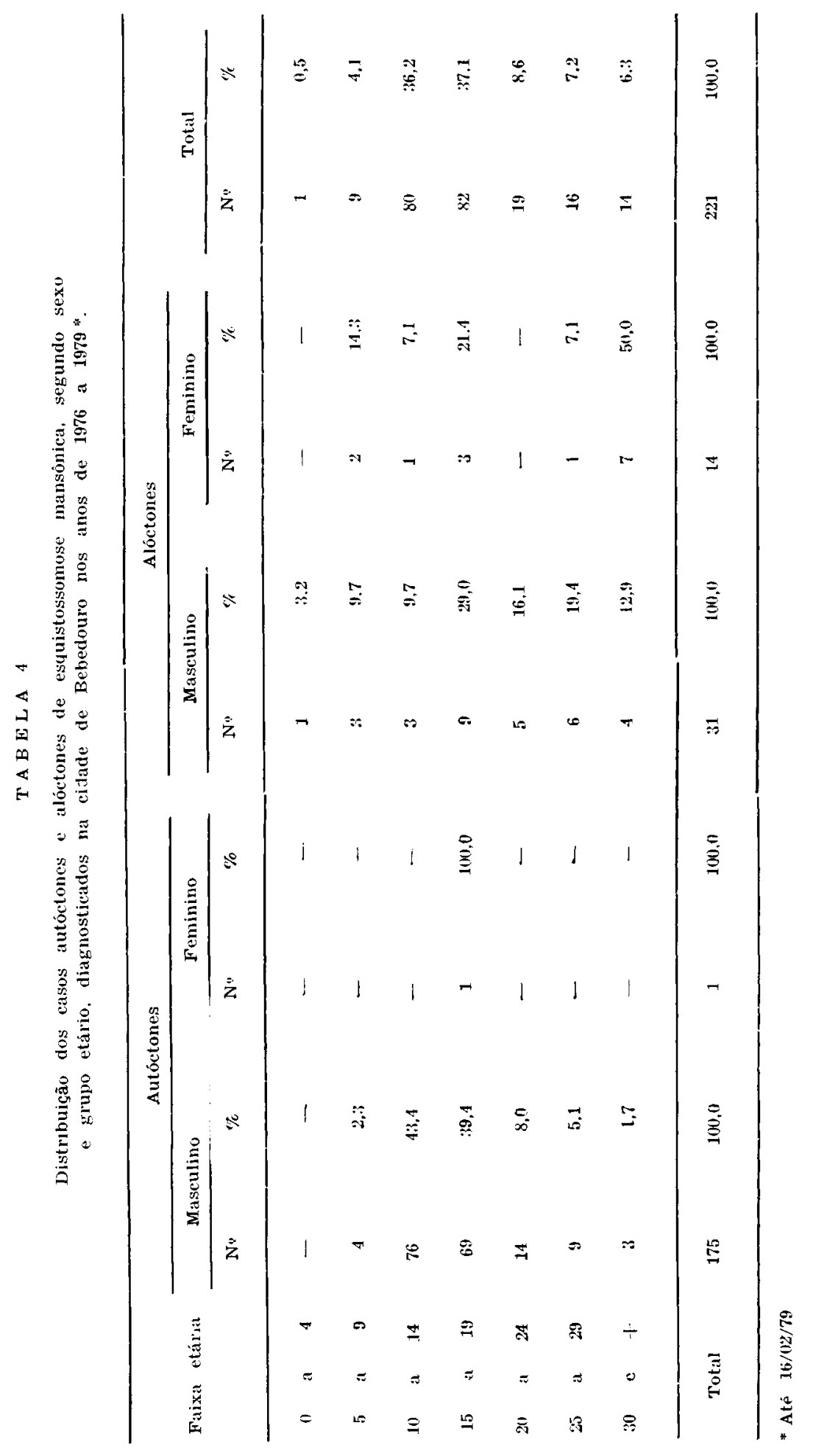


PASSOS. A. D. C. et al. Descrição de um nớn foco endèmico de esquistossomoșe niansôniçi no Estado de São Paulo. Brasil. Rer. Saúde puibl., S. Paulo. 13:341-7, 1979.

outros fatores de risco que năo apenas o lazer, demonstrando haver diferenças importantes na epidemiologia da doença quando se comparam regiōes endêmicas diversas.

\section{CONCLUSŌES}

O municipio de Bebedouro apresenta-se hoje como um novo foco endêmico de esquistossomose mansônica. A presença de coleções de águas na sua área geográfica, especialmente um lago artificial situado no periimetro urbano da cidade e onde comprovadamente existem moluscos transmissores, as más condições de saneamento $e$ a existência no local de migrantes provenientes de regiōes de alta endemicidade, devem ter sido os tatores epidemiologica- mente responsáveis pela instalaçāo do novo foco. Com o arrefecimento das medidas profiláticas inicialmente adotadas e com a persistência dos fatores anteriormente mencionados, é de se supor que a moléstia continue a se transmitir ativamente no município, estando a merecer por isso maior atenção das autoridades sanitárias responsáveis pelo controle dessa endemia.

\section{AGRADECIMENTOS}

A Nair Harumi Fumayama Takarashi, Mariângela de Vito Balbo e Maria Francisca Moreira Pires, funcionárias do Centro de Saúde de Bebedouro, pela valiosa colaboração.

Passos, A. D. C. et al. /The description of a new endemic focus of schistosomiasis mansoni in the state of S. Paulo, Brazil.] Rev. Saúde públ., S. Paulo. 13: 341-7, 1979.

ABSTRACT: A new endemic focus of schistosomiasis mansoni in the town of Bebedouro, S. Paulo, Brazil, is described. Two hundred and twenty-one cases are analyzed according to sex, age, and origin (autochthonous or not), the factors involved in the emergence of the focus are discussed and the necessity' for control measure is emphasized.

UNITERMs: Schistosomiasis, S. Paulo. SP, Brazil.

\section{REFERENCIAS BIBLIOGRAFICAS}

1. BARRETO, M. P. Movimentos migratórios e sua importância na epidemiologia de doenças parasitárias no Brasil. Ret. Soc. bras, Med, trop., 1:91-102, 1967.

2. KLOETZEL, K. Aspectos epidemiologicos da esquistossomose mansônica em uma população de Pernambuco: suas correlaçóes clinicas. São Paulo, 1962. [Te. se de Doutoramento - Faculdade de Medicina da USP].
¿. MotTA, E. G. F. da. Situação atual do controle das grandes endemias. In: Conferência Nacional de Saúde, 6a. Brasilia, 1977. Anais. Brasília, Ministério da Saúde, 1977. p. 31-101.

4. PASSOS, A. D. C. \& CARDOSO. J. C. F. Caso autóctone de esquistossomose mansônica na Região de Ribeirão Preto - Notá prétia. Med. Rer. CARL, Ribeirão Preto. 11, 1978. [no prelo]. 
PASSOS, A. D. C. et al. Descrição de um novo foco endêmico de esquistossomose mansónica no Estado de São Paulo, Brasil. Rev. Saúde públ., S. Paulo, 13:341-7. 1979.

5. PESSOA, S. B. \& AMORIN, J. P. Contribuição para a história natural da esquistossomose mansonica no Nordeste brasileiro e sugestões para a sua profilaxia. Rev, bras. Malar., 9:5-18, 1967.

6. PESSOA. S. B. \& COUTINHo. J. O. A esquistossomose mansônica como doenca do trabalho. Hospital, Rio de Janeiro, 43:429-:36. 1953.
7. SANTOS, N. R. Esquistossomose mansoni autótone no Vale do Médio Paraíba, Estado de São Paulo, Brasil. Contribuıcão para o estudo da zona endémica. São Paulo, 1967. [Tese de Doutoramento - Faculdade de Medicina da USPJ.

Recebido para publicação em 11/07/1979

Aprovado para publicação em $30 / 07 / 1979$ 